\title{
Analysis methodology and assessment indices of vulnerability for asphalt pavement in cold regions
}

\author{
Tongxu Wang, Xianyong Ma, Huanyu Li and Zejiao Dong*
}

\begin{abstract}
Asphalt pavement structures in cold regions, which suffer from complicated environmental and geological conditions, such as large temperature difference and frozen soil, are prone to cracking, rutting, and moisture damage. However, most of the existing assessment methodologies focus on the vulnerability of the overall road traffic network, ignoring the impact of regional differences and pavements' structural performance. To establish a highly targeted vulnerability analysis methodology for cold regional asphalt pavements, the concept of highway vulnerability and the assessment model composed of exposure, fragility, and resilience were proposed in this paper firstly. Meanwhile, the assessment indices and standards for exposure, fragility, and resilience were respectively discussed. Then, the calculation process for each index weight and vulnerability index was proposed based on AHPfuzzy comprehensive assessment methodology. Consequently, the vulnerability grade of asphalt pavements in cold regions could be determined. Finally, the vulnerability assessment indices and methodology for cold regional asphalt pavements were illustrated and presented, providing a theoretical basis for asphalt pavement performance evaluation and vulnerability assessment serviced under cold regional climate.
\end{abstract}

Keywords: Cold regional asphalt pavement, Vulnerability assessment, Exposure, Fragility, Resilience

\section{Introduction}

With the continuous expansion of road network coverage, the environmental and geological conditions along the highway projects are becoming increasingly complex. In cold regions where the average temperature of the coldest month is $-10{ }^{\circ} \mathrm{C}-0{ }^{\circ} \mathrm{C}$ and $33 \%$ of the days of a year have a daily average temperature below $5^{\circ} \mathrm{C}$, the differences in structural design and material properties cause different vulnerabilities for the highway system. Especially in the Qinghai-Tibet Plateau and the northern part of Heilongjiang Province in China, the widely distributed frozen soil, complex terrain conditions, and climatic characteristics are the key factors causing damage to transportation infrastructure, such as pavement

\footnotetext{
*Correspondence: hitdzj@hit.edu.cn

School of Transportation Science and Engineering, Harbin Institute of

Technology, Huanghe Road No. 73, Nangang District, Harbin, Heilongjiang 150090, PR China
}

\section{Springer Open}

deformation, landslide, and debris flow. Although some protective measures have been taken in recent years, the different vulnerabilities of the highway system under the external environment greatly increases the difficulty of construction quality control and maintenance. Therefore, it is necessary to conduct highway vulnerability assessment research.

According to natural disaster science [1], vulnerability was first defined as the degree of damage or threat to systems adversely affected by the external environment [2]. Subsequently, the concept of vulnerability has been interpreted from different perspectives by many scholars. Some believe that vulnerability is a kind of self-reaction and the ability of a system to resist adverse effects or events [3-5]. Others explain the connotation of vulnerability from a multidimensional perspective, which considers both the impact of a system's internal conditions on vulnerability and the interaction between the system

(c) The Author(s). 2021 Open Access This article is licensed under a Creative Commons Attribution 4.0 International License, which permits use, sharing, adaptation, distribution and reproduction in any medium or format, as long as you give appropriate credit to the original author(s) and the source, provide a link to the Creative Commons licence, and indicate if changes were made. The images or other third party material in this article are included in the article's Creative Commons licence, unless indicated otherwise in a credit line to the material. If material is not included in the article's Creative Commons licence and your intended use is not permitted by statutory regulation or exceeds the permitted use, you will need to obtain permission directly from the copyright holder. To view a copy of this licence, visit http://creativecommons.org/licenses/by/4.0/. 
and the external environment. Consequently, vulnerability is gradually evolving into a huge and independent conceptual system [6-9]. Some assessment models were derived from vulnerability concepts, such as the RiskHazard [10, 11], Pressure and Release [10], Hazard of Palace [12, 13], Vulnerability Scoping Diagram models $[14,15]$. Meanwhile, vulnerability assessment methodologies mainly include historical disaster data statistics, the vulnerability curve methodology, and the index system methodology [10]. Historical disaster data statistics select representative indicators and evaluate the vulnerability of a system through the statistics of historical disaster data. However, this methodology ignores natural and social factors, and could not accurately predict the long-term disaster incidence with short-term disaster data. The vulnerability curve method evaluates the relationship between disaster intensity and the affected degree of individual through the disaster damage curve. Although this method could reflect the physical sensitivity of disaster bodies and the effect of social protection measures, the accuracy of the assessment results must be improved. The index system method establishes an index system by analyzing the causes and characteristics of vulnerability, and the relationship between each index system and the vulnerability index, to evaluate the regional vulnerability. This method could reflect the vulnerability characteristics of a region comprehensively and is a conventional method for evaluating vulnerability currently.

The existing assessment models and methods are mainly applied in disaster science, and the research on highway disaster risk assessment is limited. The assessment model of highway geological disasters was established based on risk analysis theory for typical natural disasters, such as landslides and debris flows [16]. On the basis of the geographic information system (GIS) platform, the disaster vulnerability assessment model was established with the regional highway resilience index, road network density, and the unit area road output as assessment indices [17]. British Transport Research Laboratory analyzed the impact of climate change on highway vulnerability [18]. Although the vulnerability characteristics of British pavements to climate change were described, the definition and application of road vulnerability were unclear. On the basis of the GIS platform, the hazard zoning of highway geological disasters in China has been completed [19]. Ma studied the identification technology of highway flood disasters from different levels and established the identification system of highway flood disasters [20]. Xie evaluated the vulnerability of subgrade disasters by analyzing the formation mechanism of geological disasters and taking important control factors as assessment indices [21]. Few studies also simulated the performance deterioration law of pavement materials under extreme environmental conditions [22, 23], and then proposed relevant pavement material design indices. These studies addressed the highway vulnerability assessment to a certain extent. However, most of the research in the field of roads focus on the study of the overall vulnerability of road traffic network, ignoring the impact of regional differences and the pavement's structural performance.

Therefore, given the lack of vulnerability assessment system, the difficulty of obtaining index data, and the performance assessment lag, this paper establishes a vulnerability assessment methodology and an assessment index system for asphalt pavements in cold regions to provide a basis for asphalt pavement performance and vulnerability assessment under extreme climate in cold regions.

\section{Vulnerability of asphalt pavement}

In this paper, highway vulnerability refers to the nature of a highway structure, that is, the difficulty of maintaining its serviceability state due to structural damage under harsh environments [24-27]. Among the harsh environments, severe weather environment is the main reason for highway vulnerability, and the highway structure is the ontology that bears the effects of the external environment. When the ontology is damaged, the ability to maintain the serviceability state is the interaction between the external interference and the system. The pavement is the part of the highway system that directly interacts with the external environment, so evaluating the vulnerability of pavements has great significance. The vulnerability assessment of asphalt pavements should be focused on the impact of harsh climate conditions. For a reasonable and accurate vulnerability assessment, a three-stage assessment conceptual model of asphalt pavement vulnerability composed of exposurefragility-resilience was established in this study, as shown in Eq. 1. Exposure refers to the possibility and degree of pavement exposure to harsh environments, fragility reflects the degree of damage or destruction of the pavement structure, and resilience is the ability to recover to the initial state after damage under human action. The assessment standard is shown in Table 1.

$$
V=f(E, I, R)
$$

where $V$ is the pavement vulnerability index, $E$ is the exposure, $I$ is the fragility, and $R$ is the resilience.

Table 1 Assessment standard of pavement vulnerability

\begin{tabular}{llllll}
\hline Vulnerability Level & Micro & Mild & Moderate & Severe & Extreme \\
\hline$V$ & $<0.2$ & $0.2 \sim 0.4$ & $0.4 \sim 0.6$ & $0.6 \sim 0.8$ & $\geq 0.8$ \\
\hline
\end{tabular}




\section{Vulnerability assessment index system Assessment index of exposure}

Pavement exposure is reflected in the diseases and damages caused by the external environment. Climate change is not only the direct cause of pavement structure damage, but also increases the possibility and scale of pavement performance deterioration and catastrophic damage. That is, pavement structures exposed to different environments will show different vulnerability characteristics. Therefore, the main factors of exposure assessment include the extremely low temperature climate, extremely high temperature climate, extremely rainfall climate and extremely freeze-thaw days.

\section{Extremely low temperature climate}

Cold regions have frequent extremely low temperature days. Frequent temperature changes also have a great impact on asphalt pavement performance. Therefore, the extremely lowest temperature, the low temperature duration, and the daily temperature difference were selected as the assessment indices for pavement exposure.

According to the statistical data of extreme minimum temperature, average minimum temperature, and average daily temperature difference in some cold regions from 1981 to 2010, the historical extreme minimum temperature in cold regions is mainly between $-40^{\circ} \mathrm{C}$ and $-20^{\circ} \mathrm{C}$. Therefore, $-40^{\circ} \mathrm{C}$ was taken as the extreme exposure demarcation point $[28,29]$. According to the literature, $-30^{\circ} \mathrm{C}$ was taken as the moderate exposure demarcation point. Low temperature duration refers to the days when the daily minimum temperature is lower than $-30^{\circ} \mathrm{C}$, which increases with the latitude [30]. In general, the longer the duration of extreme low temperature is, the greater the impact is on asphalt pavement performance. The low temperature duration was divided into levels based on experience and research results. In addition, referring to the early warning standard of cold wave in China, the extreme daily temperature difference threshold of $16^{\circ} \mathrm{C}$ was taken as the demarcation point of moderate exposure. Then, the assessment standard of each index under the extremely low temperature climate in cold regions could be established by the linear interpolation method, as shown in Table 2 .

\section{Extremely high temperature climate}

Considering the influence of high temperature on pavement vulnerability, the extreme maximum temperature and the high temperature duration were selected as assessment indices $[28,30]$. The weather with a temperature over $32{ }^{\circ} \mathrm{C}$ is defined as a high temperature weather by the World Meteorological Organization. The high temperature duration refers to the period when the daily maximum temperature exceeds $32^{\circ} \mathrm{C}$. Therefore, $32{ }^{\circ} \mathrm{C}$ was taken as the severe exposure demarcation point. Referring to research results [30], $25^{\circ} \mathrm{C}$ was taken as the moderate exposure demarcation point, and according to the literature [28], the duration of extreme high temperature in cold region is mostly distributed in 0-15 days. Therefore, 5 days were taken as the micro exposure demarcation point, and 15 days were taken as the extreme exposure demarcation point from experience. Solar radiation and route design are also important factors for evaluating the influence of high temperature on asphalt pavement performance. Thus, the annual average solar radiation and the route design should be added as assessment indices. In the long longitudinal slope or some sections with a small turning radius, the probability of rutting increases with the high temperature. In addition, according to the radiation data of the cold region from 1981 to 2010, the annual average solar radiation is $1000-2000 \mathrm{~kW} / \mathrm{m}^{2}$. Therefore, the solar radiation was divided into levels based on experience. The route design was divided into levels according to the Design Specification for Highway Alignment (JTG D20-2017). Accordingly, the corresponding assessment standard was established by the linear interpolation method, as shown in Table 3.

\section{Extremely rainfall climate}

Frequent rainfall in summer in cold regions could easily lead to floods and aggravate pavement water damage, especially in areas with complex geological conditions. The drainage capacity of a pavement directly affects the possibility and scale of water damage to the pavement but is not the only factor. In addition to man-made drainage facilities and natural topographic conditions, the geotechnical types along the highway are also key factors to pavement vulnerability. The higher the rock and soil strength is, the lower the probability of natural disasters and the vulnerability of highways are. Therefore, the average annual rainstorm days, the pavement drainage capacity, topographic conditions, and geotechnical types were selected as assessment indices. A daily rainfall of more than $25 \mathrm{~mm}$ is considered a rainstorm in

Table 2 Assessment standard of extreme low temperature climate in cold regions

\begin{tabular}{|c|c|c|c|c|c|}
\hline Assessment Index & Micro & Mild & Moderate & Severe & Extreme \\
\hline Extremely lowest temperature $\left({ }^{\circ} \mathrm{C}\right)$ & $<-25$ & $-25 \sim-30$ & $-30 \sim-35$ & $-35 \sim-40$ & $\geq-40$ \\
\hline Low temperature duration (d) & $<5$ & $5 \sim 10$ & $10 \sim 20$ & $20 \sim 30$ & $\geq 30$ \\
\hline Daily temperature difference $\left({ }^{\circ} \mathrm{C}\right)$ & $<12$ & $12 \sim 16$ & $16 \sim 20$ & $20 \sim 24$ & $\geq 24$ \\
\hline
\end{tabular}


Table 3 Assessment standard of extreme high temperature climate in cold regions

\begin{tabular}{|c|c|c|c|c|c|}
\hline Assessment Index & Micro & Mild & Moderate & Severe & Extreme \\
\hline $\begin{array}{l}\text { Extreme maximum } \\
\text { temperature }\left({ }^{\circ} \mathrm{C}\right)\end{array}$ & $<18$ & $18 \sim 25$ & $25 \sim 32$ & $32 \sim 39$ & $\geq 39$ \\
\hline $\begin{array}{l}\text { High temperature } \\
\text { duration (d) }\end{array}$ & $<5$ & $5 \sim 8$ & $8 \sim 11$ & $11 \sim 15$ & $\geq 15$ \\
\hline $\begin{array}{l}\text { Annual average solar } \\
\text { radiation }\left(\mathrm{kW} / \mathrm{m}^{2}\right)\end{array}$ & $<1000$ & $1000 \sim 1350$ & $1350 \sim 1700$ & $1700 \sim 2000$ & $\geq 2000$ \\
\hline $\begin{array}{l}\text { Route design (Road } \\
\text { horizontal, vertical and } \\
\text { horizontal design) }\end{array}$ & $\begin{array}{l}\text { Reasonable } \\
\text { design and } \\
\text { turning radius }\end{array}$ & $\begin{array}{l}\text { Proper } \\
\text { design and } \\
\text { turning } \\
\text { radius }\end{array}$ & $\begin{array}{l}\text { Large longitudinal slope } \\
\text { or large turning radius, } \\
\text { the deviation } \leq 10 \%\end{array}$ & $\begin{array}{l}\text { Large longitudinal slope or } \\
\text { large turning radius, the } \\
\text { deviation between 10\%-20\% }\end{array}$ & $\begin{array}{l}\text { Poor design or large } \\
\text { turning radius, and } \\
\text { deviation } \geq 30 \%\end{array}$ \\
\hline
\end{tabular}

this study. The annual rainstorm days refer to average of rainstorm days per year, which is related to the number of statistical years.

The corresponding assessment standards have been proposed for the drainage capacity of slope, protection engineering, and highway bridges in the Technical Code for Highway Maintenance (JTG H10-2009). The topographic condition directly affects the drainage capacity of highway infrastructure, and includes the topographic slope and the surface incision depth. When the terrain slope is less than $8^{\circ}$, the influence on the stability of the highway slope is the lowest, and the probability of geological disasters is small. When the terrain slope exceeds $35^{\circ}$, geological disasters are likely to occur [16]. Therefore, $8^{\circ}$ and $35^{\circ}$ were selected as the demarcation points of mild and extreme exposures, respectively, and the average annual rainstorm days and the terrain slope could be divided based on experience. The surface incision depth refers to the difference between the average elevation of a certain point on the ground and the minimum elevation in the neighborhood. The slope is extremely unstable when the surface incision depth exceeds $700 \mathrm{~m}$, and the impact on the slope is small within $100 \mathrm{~m}$. Then, the levels could be determined by the linear interpolation method. Geotechnical engineering characteristics are important material conditions and control factors of natural highway disasters. Under the same terrain conditions, hard rock has high strength, a strong anti-erosion ability, and a low highway vulnerability, and the assessment standard could be divided according to the strength. The final assessment standard for extreme rainfall climate in cold regions is shown in Table 4.

\section{Extremely freeze-thaw days}

In cold regions, the differences in permafrost characteristics directly affect the stability of the subgrade and the slope. The snow on the pavement surface will melt with the increase of temperature, which could increase the possibility of water damage and affect the driving safety. The asphalt pavement is prone to cracking under the freeze-thaw cycle, which has a great impact on pavements' structure performance. Therefore, the characteristics of permafrost, the freeze-thaw days, and the blizzard frequency were selected as assessment indices. The freeze-thaw days refer to the times of freeze-thaw

Table 4 Assessment standard of extreme rainfall climate in cold regions

\begin{tabular}{|c|c|c|c|c|c|}
\hline $\begin{array}{l}\text { Assessment } \\
\text { Index }\end{array}$ & Micro & Mild & Moderate & Severe & Extreme \\
\hline $\begin{array}{l}\text { Average } \\
\text { annual } \\
\text { rainstorm } \\
\text { days (d) }\end{array}$ & $<3$ & $3 \sim 5$ & $5 \sim 9$ & $9 \sim 11$ & $\geq 11$ \\
\hline $\begin{array}{l}\text { Pavement } \\
\text { drainage } \\
\text { capacity }\end{array}$ & $\begin{array}{l}\text { Reasonable } \\
\text { pavement } \\
\text { drainage system } \\
\text { and location of } \\
\text { bridges }\end{array}$ & $\begin{array}{l}\text { Reasonable pavement } \\
\text { drainage system and } \\
\text { location of bridges, } \\
\text { bridge aperture } \\
\text { deviation } \leq 10 \%\end{array}$ & $\begin{array}{l}\text { Poor pavement drainage } \\
\text { system and good location } \\
\text { of bridges, bridge aperture } \\
\text { deviation between 10\%-- } \\
20 \%\end{array}$ & $\begin{array}{l}\text { Poor pavement drainage } \\
\text { system and unreasonable } \\
\text { location of bridges, bridge } \\
\text { aperture deviation between } \\
10 \%-20 \%\end{array}$ & $\begin{array}{l}\text { Inadequate pavement } \\
\text { drainage system and } \\
\text { deviated location of } \\
\text { bridges, bridge aperture } \\
\text { deviation }>20 \%\end{array}$ \\
\hline $\begin{array}{l}\text { Terrain slope } \\
\left({ }^{\circ}\right)\end{array}$ & $<8$ & $8 \sim 15$ & $15 \sim 25$ & $25 \sim 35$ & $\geq 35$ \\
\hline $\begin{array}{l}\text { Surface } \\
\text { incision } \\
\text { depth (m) }\end{array}$ & $<100$ & $100 \sim 300$ & $300 \sim 500$ & $500 \sim 700$ & $\geq 700$ \\
\hline $\begin{array}{l}\text { Geotechnical } \\
\text { types }\end{array}$ & Hard rock & Medium hard rock & Soft rock & Earth-rock aggregate & Loose oil \\
\hline
\end{tabular}


damage caused by the plus-minus changeable temperature in a day. The number of blizzard refers to the number of times the snowfall exceeded $10 \mathrm{~mm}$, and blizzard frequency is the ratio of the number of blizzards to the total number of snowfalls.

According to research results, 54 and 72 days were selected as the demarcation points of the mild and extreme exposures, respectively [28]. The blizzard frequency was divided into five levels based on experience. The characteristics of permafrost could be characterized by the permafrost temperature and the ice content of permafrost [31]. The higher the values of the two factors are, the worse the engineering stability is. Considering the annual average ground temperature range of permafrost in cold regions, $-3^{\circ} \mathrm{C}$ and $-0.5^{\circ} \mathrm{C}$ were selected as the mild and severe exposure demarcations, respectively. Then, the corresponding assessment standard of each index could be established by the linear interpolation method, as shown in Table 5.

\section{Assessment index of fragility}

Pavement fragility refers to the degree of difficulty with which the pavement is damaged by external influences. Pavement fragility is obviously different from different material, structure and service status. The main factors of fragility assessment include the actual pavement damage state and the structural performance.

\section{Pavement surface damage}

The main damage of asphalt pavements in cold regions is cracks, especially low-temperature cracks. Thus, the pavement crack index was selected as an assessment index. The pavement crack index refers to the number of full-width shrinkage cracks plus half of the number of half-width transverse cracks within $100 \mathrm{~m}$ of two lanes. When the pavement crack index exceeds 25 , the pavement is seriously damaged, and the ability to resist external interference is very poor $[32,33]$. According to the design standard of pavement allowable crack index, the assessment standard of pavement crack index is determined by the linear interpolation method, as shown in Table 6.
Table 6 Assessment standard of pavement crack index

\begin{tabular}{llllll}
\hline Assessment Index & Micro & Mild & Moderate & Severe & Extreme \\
\hline Crack index & $<6$ & $6 \sim 12$ & $12 \sim 18$ & $18 \sim 25$ & $\geq 25$ \\
\hline
\end{tabular}

\section{Pavement structural performance}

Under repeated temperature change, the temperature stress inside the pavement gradually increases, and the ultimate tensile strength of the asphalt mixture decreases. Cracks appear when the temperature stress exceeds the ultimate tensile strength of the asphalt mixture. Therefore, the pavement temperature fatigue performance was selected as the main assessment index of pavement structure performance. For some cold regions with heavy traffic and a large annual temperature difference, pavement fatigue performance under load and permanent deformation should be added as comprehensive assessment indices.

In summary, based on the Miner criterion [34], the cumulative damage degrees of pavement temperature fatigue, load fatigue, and permanent deformation should be calculated and evaluated. According to research results, 0.4 and 0.8 were selected as the demarcation points of moderate and extreme exposures, respectively, and the levels could be determined by the linear interpolation method [34]. In addition, the pavement performance decreases with the increase in service time, so the remaining service life of the structure should be selected as the assessment index. The remaining service life refers to the difference between the designed service life and the service time of the pavement, which is expressed in percentage. It reflects the influence of time on the performance of the pavement structure. The cumulative damage degrees and the remaining service life could be divided into five equal levels from experience. Finally, the assessment standard of pavement structure performance is established as shown in Table 7.

\section{Assessment index of resilience}

The material and structural properties gradually decrease with the increase of service time, the resilience of materials and structures against adverse deformation or damage is small and could be ignored. The resilience of highways is mainly composed of maintenance and

Table 5 Assessment standard of extreme freeze-thaw days in cold regions

\begin{tabular}{|c|c|c|c|c|c|}
\hline Assessment Index & Micro & Mild & Moderate & Severe & $\overline{\text { Extreme }}$ \\
\hline Freeze-thaw days (d) & $<54$ & $54 \sim 60$ & $60 \sim 66$ & $66 \sim 72$ & $\geq 72$ \\
\hline The frequency of blizzard & $<0.2$ & $0.2 \sim 0.4$ & $0.4 \sim 0.6$ & $0.6 \sim 0.8$ & $\geq 0.8$ \\
\hline Permafrost temperature $\left({ }^{\circ} \mathrm{C}\right)$ & $<-3$ & $-3 \sim-1.5$ & $-1.5 \sim-0.5$ & $-0.5 \sim 0$ & $>0$ \\
\hline Ice content of permafrost & $S, D, F$ & $S, D, F$ & $S, D, F$ & $S, D, F$ & $B, H$ \\
\hline
\end{tabular}

1) $\mathrm{S}$ refers to less ice, $\mathrm{D}$ refers to more ice, $\mathrm{F}$ refers to rich ice, $\mathrm{B}$ refers to saturated ice, and $\mathrm{H}$ refers to soil ice. 2) When a certain ground temperature is combined with $\mathrm{B}$ or $\mathrm{H}$, it should be classified as the next level. For example, when the permafrost temperature is lower than $-3^{\circ} \mathrm{C}$ and the ice content is $\mathrm{B}$ or $\mathrm{H}$, the exposure is mild 
Table 7 Assessment standard of pavement fatigue damage based on the miner criterion

\begin{tabular}{llllll}
\hline Assessment Index & Micro & Mild & Moderate & Severe & Extreme \\
\hline Cumulative damage degrees & $<0.2$ & $0.2 \sim 0.4$ & $0.4 \sim 0.6$ & $0.6 \sim 0.8$ & $\geq 0.8$ \\
The remaining service life (\%) & $\geq 0.8$ & $0.6 \sim 0.8$ & $0.4 \sim 0.6$ & $0.2 \sim 0.4$ & $<0.2$ \\
\hline
\end{tabular}

management, such as crack repair and asphalt overlay. That is, resilience could be evaluated from two aspects, namely, maintenance strength and maintenance effect.

Generally, the greater the intensity of financial investment in a region is, the better the regional economic development and the stronger the ability to recover after damage are. Hence, the financial investment of regional departments, the regional economic development, and the assessment of pavement repair and re-damage after repair were analyzed, and the corresponding assessment standard is shown in Table 8.

\section{Assessment methodology of asphalt pavement vulnerability in cold regions}

In summary, the assessment index system of asphalt pavement vulnerability in cold regions is shown in Fig. 1.

\section{Vulnerability assessment methodology and process AHP-fuzzy comprehensive evaluation method}

To obtain the weight of each assessment index and the vulnerability index, the analytic hierarchy process (AHP)-fuzzy comprehensive evaluation method was adopted, and the calculation principle is shown in Fig. 2. The following are the specific steps [35]:

1) Factor set $U=\left\{u_{1}, u_{2}, \ldots, u_{m}\right\}$ and comment set $V=\left\{v_{1}, v_{2}, \ldots, v_{n}\right\}$ of the evaluation object are determined.

2) The fuzzy relationship matrix $\mathrm{R}$ between $U$ and $V$, that is, the membership matrix, could be constructed by qualitative or quantitative methods.

3) On the basis of the AHP, the weight of each factor in $U$ could be determined to obtain weight matrix $A$.
4) Through the fuzzy transformation formula $A$ $R=B$, the assessment results are obtained according to the maximum membership principle.

On the basis of the AHP-fuzzy comprehensive evaluation method, the membership degree of pavement vulnerability could be calculated by Eq. 2 .

$$
S_{V}=\left(\omega_{E} \omega_{F} \omega_{R}\right)\left(S_{E} S_{F} S_{R}\right)^{\prime}
$$

where $S_{V}$ is the membership matrix of pavement vulnerability, $S_{E}$ is the membership matrix of pavement exposure, $S_{F}$ is the membership matrix of pavement fragility, $S_{R}$ is the membership matrix of pavement resilience, $\omega_{E}$ is the weight of pavement exposure, $\omega_{F}$ is the weight of pavement fragility, and $\omega_{R}$ is the weight of pavement resilience.

According to the maximum membership degree, pavement vulnerability index $V$ could be calculated by Eq. 3, and the vulnerability assessment of asphalt pavements could be analyzed in combination with Table 1 .

$$
V=a_{i}+0.2 s_{v}
$$

where $a_{i}$ is the lower bound of the interval corresponding to the vulnerability grade; $i=1, \ldots, 5$; and $s_{v}$ is the maximum membership degree of pavement vulnerability.

\section{The process of vulnerability assessment}

In the vulnerability analysis of asphalt pavements, the corresponding index should be selected according to the actual service environment of the evaluated section. The vulnerability assessment process of asphalt pavements in cold regions proposed in this work includes the identification of vulnerability factors, the determination of assessment

\begin{tabular}{|c|c|c|c|c|c|}
\hline Assessment Index & Extreme & Severe & Moderate & Mild & Micro \\
\hline $\begin{array}{l}\text { Regional } \\
\text { financial } \\
\text { investment }\end{array}$ & $\begin{array}{l}\text { Timely and effective disaster } \\
\text { assessment and adequate } \\
\text { investment }\end{array}$ & $\begin{array}{l}\text { Effective disaster } \\
\text { assessment and many } \\
\text { investment }\end{array}$ & $\begin{array}{l}\text { Good disaster } \\
\text { assessment and } \\
\text { average investment }\end{array}$ & $\begin{array}{l}\text { Incomplete disaster } \\
\text { assessment and less } \\
\text { investment }\end{array}$ & $\begin{array}{l}\text { Incomplete disaster } \\
\text { assessment and little } \\
\text { investment }\end{array}$ \\
\hline $\begin{array}{l}\text { Regional } \\
\text { economic } \\
\text { development }\end{array}$ & Developed & Relatively developed & Average & Relatively backward & Backward \\
\hline $\begin{array}{l}\text { Pavement } \\
\text { maintenance }\end{array}$ & Rapid treatment & Timely treatment & Not timely treatment & Belated treatment & $\begin{array}{l}\text { Long-term non- } \\
\text { treatment }\end{array}$ \\
\hline $\begin{array}{l}\text { Re-damage } \\
\text { condition }\end{array}$ & None & A few & Within half & Over half & Most \\
\hline
\end{tabular}

Table 8 Assessment standard of maintenance strength 


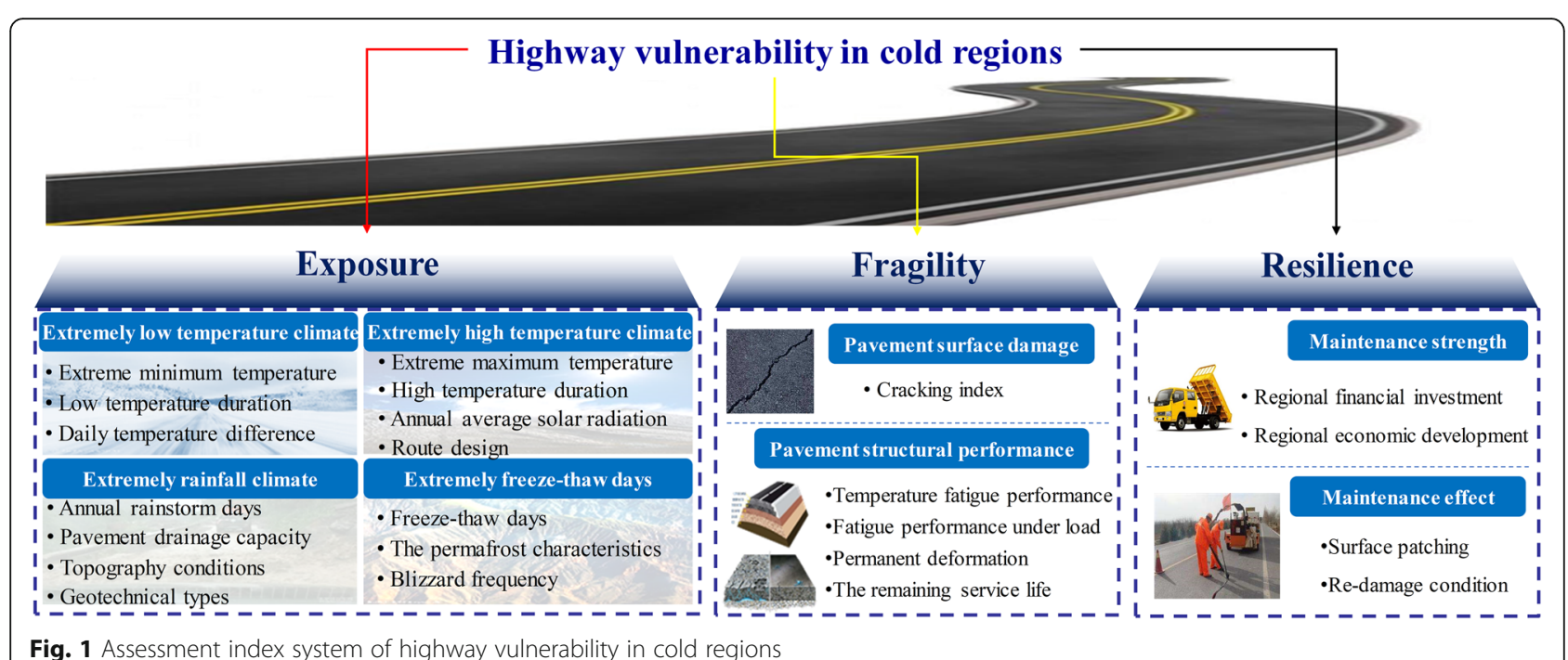

indices, the assessment of real-time pavement service capacity, and the assessment of asphalt pavement vulnerability under extreme climate, as shown in Fig. 3.

First, the vulnerability factors were identified to determine the external and internal factors leading to pavement vulnerability. The main sources of data include the statistical data of meteorological and geological conditions, monitoring data, and field research data. The meteorological and geological characteristics along the pavement, including the temperature, the rainfall, the solar radiation, the permafrost distribution, the topography, and the geotechnical types, were identified and analyzed. Then, the route design, the pavement structure combination, and the traffic distribution characteristics were investigated and analyzed.

Second, according to the identification results, the extreme climate types and pavement damage characteristics could be determined to select appropriate assessment indices. In other words, the pavement exposure index should be determined according to the selected extreme climate, and the pavement fragility index should be determined according to the analysis of pavement damage characteristics under extreme climate. Finally, the assessment index of pavement resilience should be determined based on the local social and natural factors.

Then, the real-time service performance and actual service state of the pavement could be studied with the selected fragility assessment indices and in situ measurement data. The pavement crack condition should be investigated to calculate the pavement cracking rate. Combined with the temperature field of the pavement, the temperature fatigue life could be calculated and evaluated. Similarly, the fatigue life and permanent deformation under load could be calculated and evaluated using the measured data. Finally, the remaining life of the pavement could be obtained using the actual service time.

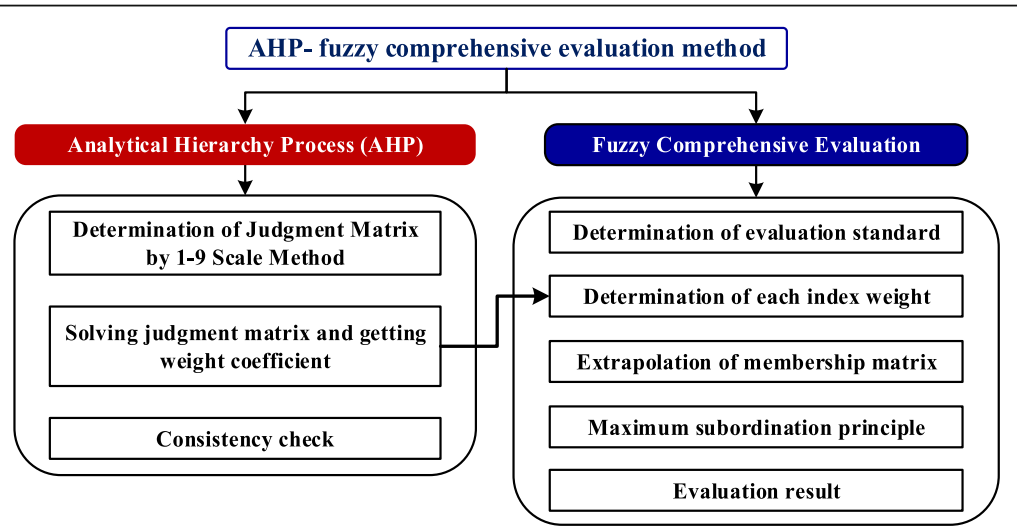

Fig. 2 The calculation process of AHP-fuzzy comprehensive method 


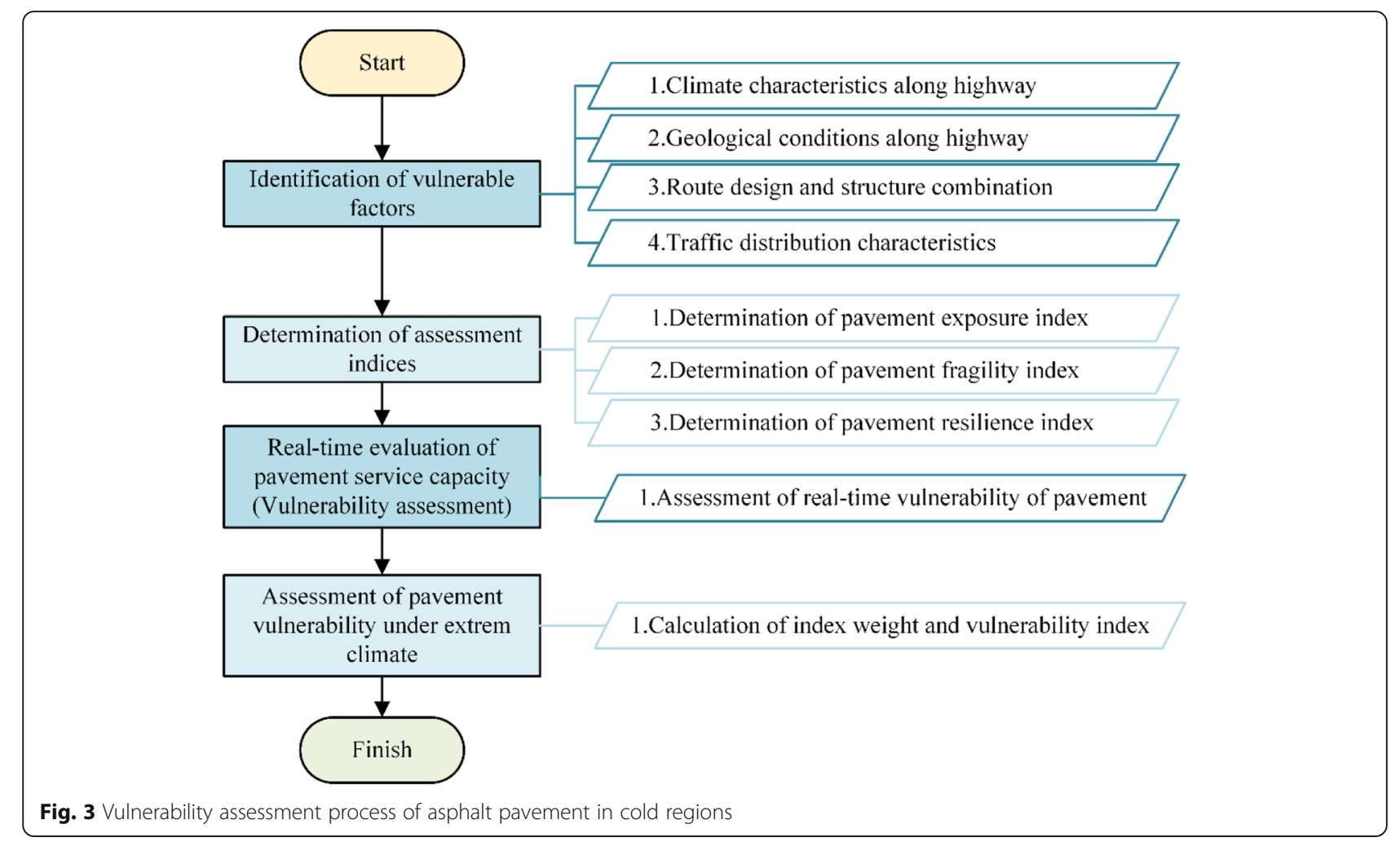

Finally, according to the AHP-fuzzy comprehensive evaluation method, the weight of pavement exposure, fragility and resilience indices, and the vulnerability index could be obtained. The real-time assessment of pavement vulnerability under extreme climate in cold regions could be realized.

\section{Weight of assessment indices}

The importance of each index was investigated through questionnaire survey. The questionnaire items were scored 1-5 depending on the importance of each index in
Tables 10 and 11 . Six types of respondents who are mainly engaged in the research on asphalt pavements in cold regions were selected, including college teachers, postgraduate students, researchers, enterprise experts, practitioners, and others. A total of 66 valid questionnaires were collected from 100 questionnaires issued, and the result is reliable because of the universality of the respondents. The proportion distribution of the respondents is shown in Fig. 4.

According to the principle of AHP, the weight of each index of vulnerability for asphalt pavements in cold

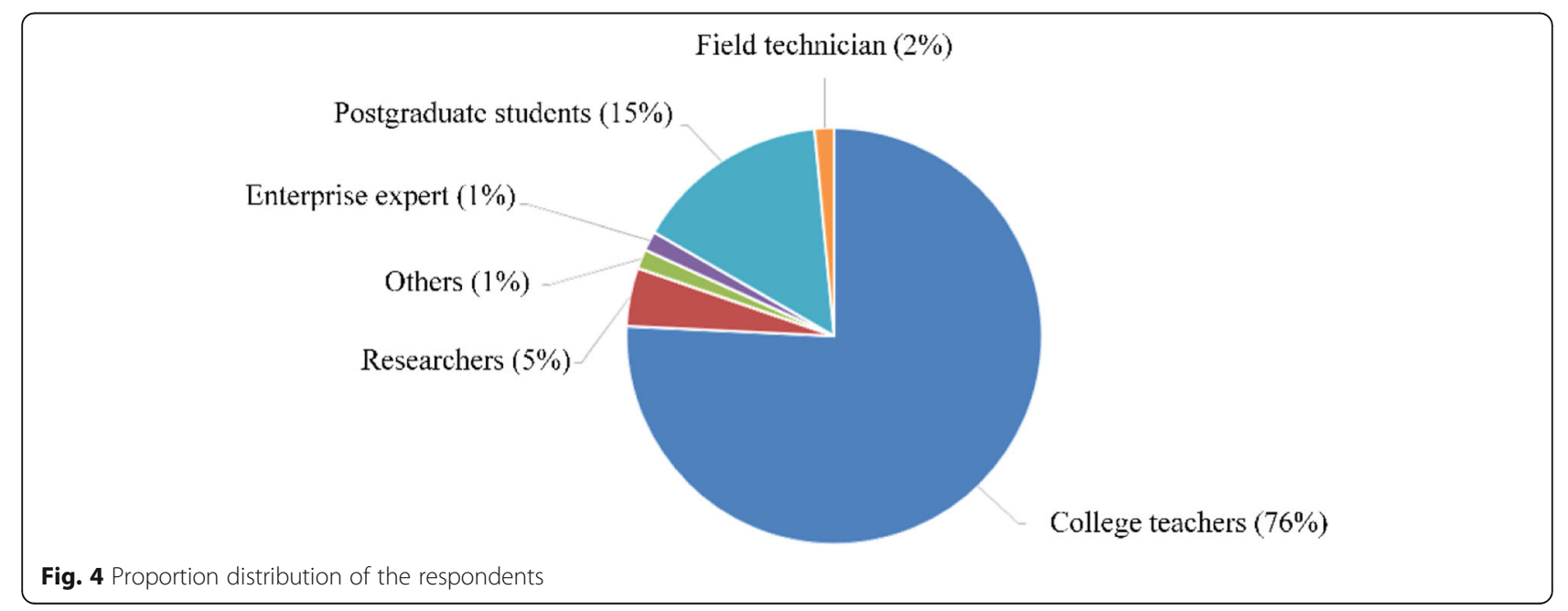


regions could be obtained by the survey results, as shown in Tables 9, 10 and 11.

\section{Vulnerability assessment of asphalt pavement under extreme high temperature climate}

Given that continuous low temperature has little effect on pavement performance, the pavement is prone to damage when the temperature suddenly rises to $40{ }^{\circ} \mathrm{C}$ in perennially low temperature region. Therefore, this extreme climate was selected for vulnerability analysis. According to the proposed vulnerability assessment methodology, the vulnerability of asphalt pavements under extremely high temperature climate was conducted in the GIS platform and using the scenario analysis methodology. The evaluated pavement is located in Huma in Heilongjiang Province, China where the probability of extreme high temperature in summer is high. Under such high temperature and load, a large strain could be usually generated inside the pavement, and the fatigue failure probability is high.

First, the vulnerability factors were identified according to the service environment of the pavement in Huma, and the assessment index system was determined as shown in Fig. 5 . As one of the extreme climate return period analysis methods, the Pearson type III curve prediction method is widely used because its prediction results are consistent with the actual hydrological phenomena in China. On the basis of the 30-year (1990-2019) daily high temperature data of seven stations in Heilongjiang Province obtained by the China Meteorological data network, the theoretical frequency curve of the historical data could be obtained, and the predicted values of events under different frequencies could be calculated using Eqs. 4 and 5. Then, the prediction curve could be matched with the historical data curve by adjusting the deviation coefficient of the Pearson type III curve method. The matching results passed the significance test, and the Pearson correlation coefficient of temperature from each station exceeded 90\%, indicating that the Pearson type III curve method is reasonable. Finally, two vulnerability analysis cases, namely, once in 20 years (Case 1) and once in a hundred years (Case 2), were designed, as shown in Figs. 6 and 7 , respectively.

$$
\begin{aligned}
x_{P} & =\left(\Phi C_{V}+1\right) \cdot \bar{x} \\
C_{V} & =\frac{1}{\bar{x}} \sqrt{\frac{1}{n-1} \sum_{i=1}^{n}\left(x_{i}-\bar{x}\right)^{2}}
\end{aligned}
$$

Table 9 Weight of first grade indices of pavement vulnerability

\begin{tabular}{lcc}
\hline Pavement Exposure & Pavement Fragility & Pavement Resilience \\
\hline 0.5193 & 0.3078 & 0.1729 \\
\hline
\end{tabular}

where $x_{P}$ is the prediction value under the probability of $\mathrm{p} ; \bar{x}$ is the average of the historical data; $\Phi$ is the deviation coefficient; $C_{V}$ is the coefficient of variation; $x_{i}$ is the historical data; $i=1, \ldots, n$, and $n$ is the total data.

In Case 1, the extreme maximum temperature in Huma was between $34{ }^{\circ} \mathrm{C}$ and $35^{\circ} \mathrm{C}$, which could be classified as severe exposure according to Table 3. The duration of high temperature was between 13 and 15 days, indicating severe exposure. In Case 2, the extreme maximum temperature exceeded $39^{\circ} \mathrm{C}$, which could be classified as extreme exposure. The duration of high temperature was approximately 19 days to 23 days, indicating extreme exposure. Meanwhile, according to the radiation statistics from 2010 to 2019, the average annual radiation in the region was approximately 61.80 $\mathrm{kW} / \mathrm{m}^{2}$, indicating micro exposure. The membership matrixes of pavement exposure are shown in Eqs. 6 and 7.

$$
\begin{aligned}
& R_{C 1-U}^{\text {Case } 1}=\left(\begin{array}{lllll}
0 & 0 & 0 & 1 & 0 \\
0 & 0 & 0 & 1 & 0 \\
1 & 0 & 0 & 0 & 0
\end{array}\right) \\
& R_{C 1-U}^{\text {Case } 2}=\left(\begin{array}{lllll}
0 & 0 & 0 & 0 & 1 \\
0 & 0 & 0 & 0 & 1 \\
1 & 0 & 0 & 0 & 0
\end{array}\right)
\end{aligned}
$$

Six full-width and one half-width cracks of the selected pavement were investigated and analyzed. The crack width was basically greater than $2.5 \mathrm{~cm}$, and the crack index was approximately 6.5 , which could be classified as mild fragility according to Tables 6 and 7. The calculated pavement damage rate was 1.8 , and the load fatigue damage degree was $4.04 \times 10^{-11}$, indicating micro fragility. The remaining service life of the pavement was 0.96 , also indicating micro fragility. The membership matrix of pavement fragility is shown in Eqs. 8 and 9.

$$
\begin{aligned}
& R_{C 2-U}=\left(\begin{array}{lllll}
0 & 1 & 0 & 0 & 0
\end{array}\right) \\
& R_{C 3-U}=\left(\begin{array}{lllll}
1 & 0 & 0 & 0 & 0 \\
1 & 0 & 0 & 0 & 0
\end{array}\right)
\end{aligned}
$$

According to the investigation data, the membership matrixes of pavement resilience are shown in Eqs. 10 and 11.

$$
\begin{aligned}
& R_{C 4-U}=\left(\begin{array}{lllll}
0 & 1 & 0 & 0 & 0 \\
0 & 0 & 0 & 1 & 0
\end{array}\right) \\
& R_{C 5-U}=\left(\begin{array}{lllll}
0 & 0 & 0 & 1 & 0
\end{array}\right)
\end{aligned}
$$

The weight of pavement exposure indices could be obtained through Table 10, and the membership degree of pavement exposure under different scenarios could be calculated. At extreme high temperatures in 
Table 10 Weight of pavement exposure indices

\begin{tabular}{|c|c|c|c|c|}
\hline First grade indices & Second indices & Weight & Third grade indices & Weight \\
\hline \multirow[t]{14}{*}{ Pavement exposure } & Extreme low temperature climate & 0.4065 & Extreme minimum temperature & 0.4562 \\
\hline & & & Low temperature duration & 0.2934 \\
\hline & & & Daily temperature difference & 0.2504 \\
\hline & Extreme high temperature climate & 0.2148 & Extreme maximum temperature & 0.4215 \\
\hline & & & High temperature duration & 0.2716 \\
\hline & & & Annual average solar radiation & 0.1918 \\
\hline & & & Route design & 0.1151 \\
\hline & Extreme rainfall climate & 0.1289 & Annual rainstorm days & 0.4447 \\
\hline & & & Pavement drainage capacity & 0.2537 \\
\hline & & & Topography conditions & 0.1750 \\
\hline & & & Geotechnical types & 0.1266 \\
\hline & Extreme freeze-thaw days & 0.2499 & Freeze-thaw days & 0.3172 \\
\hline & & & The permafrost characteristics & 0.4355 \\
\hline & & & Blizzard frequency & 0.2473 \\
\hline
\end{tabular}

Case 1, the membership matrix of pavement exposure could be calculated by Eqs. 12 and 13 .

$$
\begin{aligned}
\omega_{C 1-U} & =\left(\begin{array}{llll}
0.4763 & 0.3069 & 0.2168
\end{array}\right) \\
R_{B 1}^{\text {Case } 1} & =R_{C 1}^{\text {Case } 1}=\omega_{C 1-U^{\circ} R_{C 1-U}^{C a s e 1}} \\
& =\left(\begin{array}{lllll}
0.2168 & 0 & 0 & 0.7832 & 0
\end{array}\right)
\end{aligned}
$$

At extreme high temperatures in Case 2, the membership matrix of pavement exposure could be calculated by Eq. 14 .

$$
\begin{aligned}
R_{B 1}^{\text {Case } 2} & =R_{C 1}^{\text {Case } 2}=\omega_{C 1-U}{ }^{\circ} R_{C 1-U}^{\text {Case } 2} \\
& =\left(\begin{array}{lllll}
0.2168 & 0 & 0 & 0 & 0.7832
\end{array}\right)
\end{aligned}
$$

The weight of fragility index could be obtained through Table 11. Then, the membership matrix of asphalt pavement fragility could be calculated by Eqs. 15-18.

$$
\omega_{C 3-U}=\left(\begin{array}{ll}
0.6449 & 0.3551
\end{array}\right)
$$

$$
\begin{aligned}
R_{B 2-C} & =\left(\begin{array}{lllll}
0 & 1 & 0 & 0 & 0 \\
1 & 0 & 0 & 0 & 0
\end{array}\right) \\
\omega_{B 2-C} & =\left(\begin{array}{llll}
0.6952 & 0.3048
\end{array}\right) \\
R_{B 2} & =\omega_{B 2-C^{\circ} R_{B 2-C}} \\
& =\left(\begin{array}{lllll}
0.3048 & 0.6952 & 0 & 0 & 0
\end{array}\right)
\end{aligned}
$$

According to the principle of fuzzy comprehensive evaluation, the membership matrix of pavement resilience could be established through qualitative analysis and calculated by Eqs. 19-23.

$$
\begin{aligned}
& \omega_{C 4-U}=\left(\begin{array}{ll}
0.631 & 0.369
\end{array}\right) \\
& \omega_{B 3-C}=\left(\begin{array}{ll}
0.6559 & 0.3441
\end{array}\right) \\
& R_{C 4}=\omega_{C 4-U^{\circ}} R_{C 4-U} \\
& =\left(\begin{array}{lllll}
0 & 0.631 & 0 & 0.369 & 0
\end{array}\right)
\end{aligned}
$$

Table 11 Weight of pavement fragility index and resilience indices

\begin{tabular}{lllll}
\hline First grade indices & Second indices & Weight & Third grade indices & Weight \\
\hline $\begin{array}{l}\text { Pavement } \\
\text { Fragility }\end{array}$ & Pavement surface damage & 0.6952 & Cracking rate & 1 \\
& Pavement structural performance & 0.3048 & Temperature fatigue performance & 0.4165 \\
& & & Fatigue performance under load & Permanent deformation \\
& & & The remaining service life & 0.1872 \\
Pavement Resilience & Maintenance strength & 0.6559 & Regional financial investment & 0.1407 \\
& & & Regional economic development & 0.369 \\
& Maintenance effect & 0.3441 & Surface patching effects & 0.6431 \\
\hline
\end{tabular}




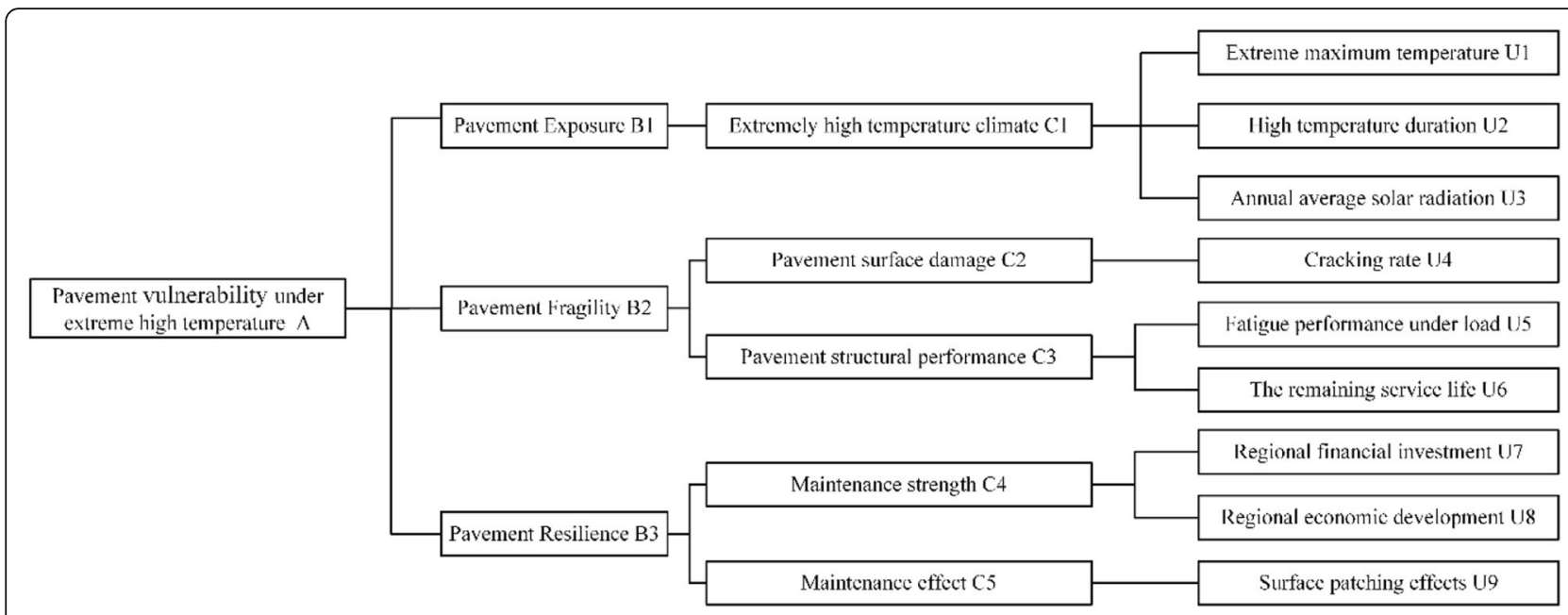

Fig. 5 Assessment index system of asphalt pavement under extreme high temperature climate

$$
\begin{aligned}
& R_{B 3-C}=\left(\begin{array}{ccccc}
0 & 0.631 & 0 & 0.369 & 0 \\
0 & 0 & 0 & 1 & 0
\end{array}\right) \\
& R_{B 3}=\omega_{B 3-C^{\circ}} R_{B 3-C}=\left(\begin{array}{llllll}
0.6559 & 0.3441
\end{array}\right) \cdot\left(\begin{array}{ccccc}
0 & 0.631 & 0 & 0.369 & 0 \\
0 & 0 & 0 & 1 & 0
\end{array}\right) \\
&=\left(\begin{array}{lllll}
0 & 0.4139 & 0 & 0.5861 & 0
\end{array}\right)
\end{aligned}
$$

Therefore, the membership matrix of pavement vulnerability could be calculated by Eqs. 24-26.

$$
R_{A-B}^{\text {Case } 1}=\left(\begin{array}{ccccc}
0.2168 & 0 & 0 & 0.7832 & 0 \\
0.3048 & 0.6952 & 0 & 0 & 0 \\
0 & 0.4139 & 0 & 0.5861 & 0
\end{array}\right)
$$

$$
R_{A-B}^{\text {Case } 2}=\left(\begin{array}{ccccc}
0.2168 & 0 & 0 & 0 & 0.7832 \\
0.3048 & 0.6952 & 0 & 0 & 0 \\
0 & 0.4139 & 0 & 0.5861 & 0
\end{array}\right)
$$

$$
\omega_{A-B}=\left(\begin{array}{lll}
0.5193 & 0.3078 & 0.1729
\end{array}\right)
$$

where $R_{A-B}^{\text {Case } 1}$ is the membership matrix of pavement vulnerability in Case $1, R_{A-B}^{\text {Case } 2}$ is the membership matrix of pavement vulnerability in Case 2 , and $\omega_{A-B}$ is the weight of membership matrix of pavement vulnerability.

Then, the membership matrices of pavement vulnerability under extreme high temperatures in the two cases are shown in Eqs. 27 and 28.

$$
R_{A}^{\text {Case } 1}=\left(\begin{array}{lllll}
0.2064 & 0.2855 & 0 & 0.5081 & 0
\end{array}\right)
$$

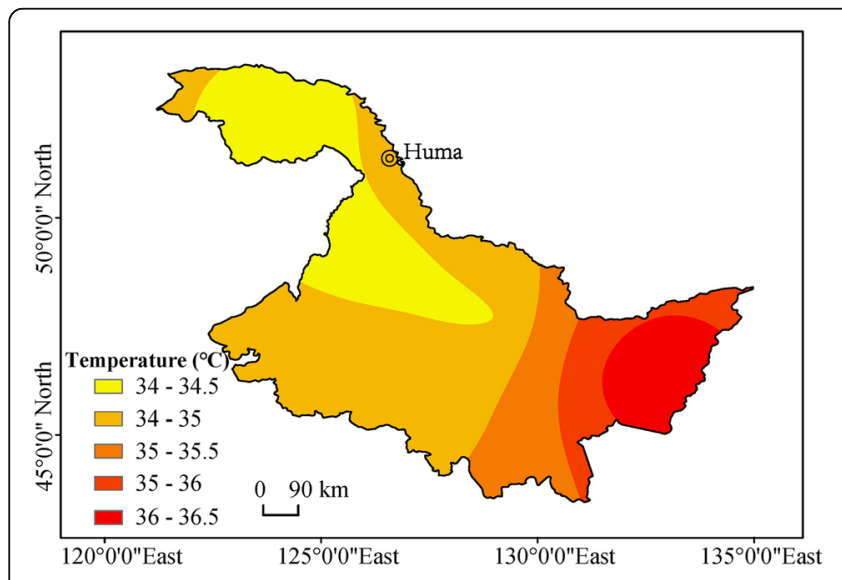

a) Distribution of extreme high temperature

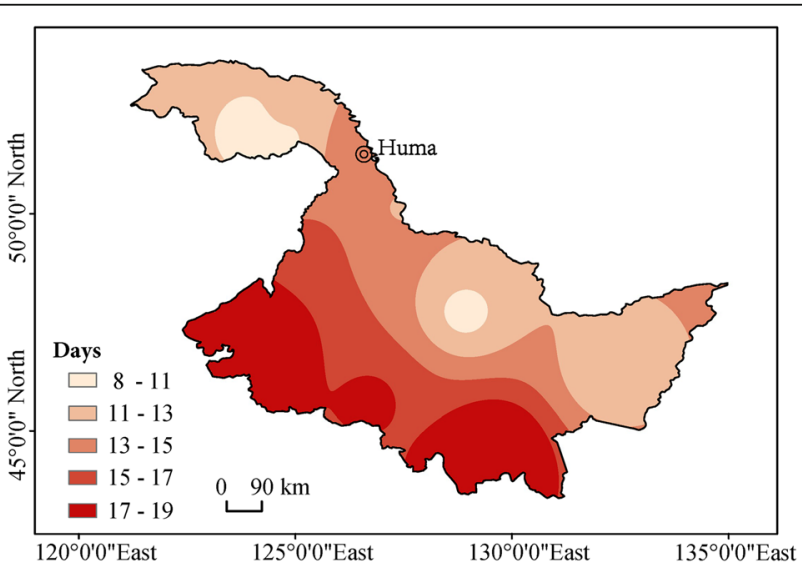

b) Distribution of high temperature duration

Fig. 6 Analysis scenario of once in twenty years (Case 1). a Distribution of extreme high temperature. $\mathbf{b}$ Distribution of high temperature duration 


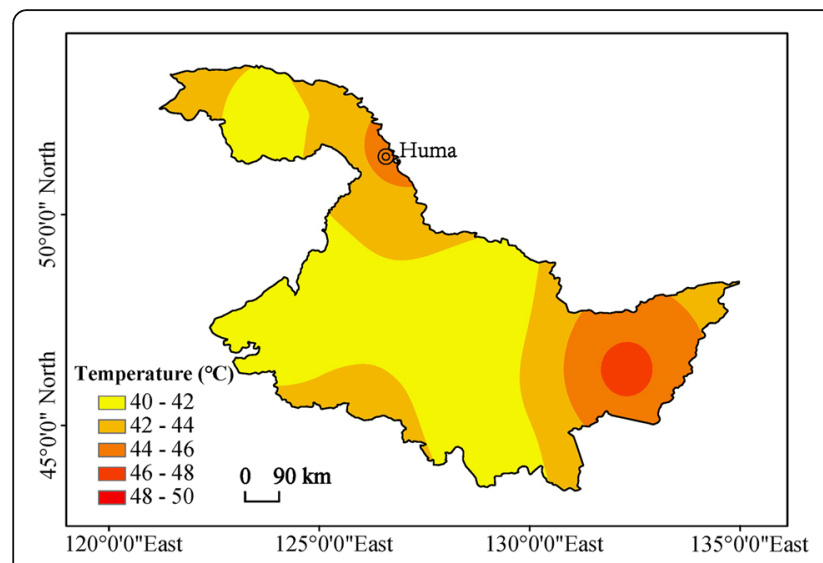

a) Distribution of extreme high temperature

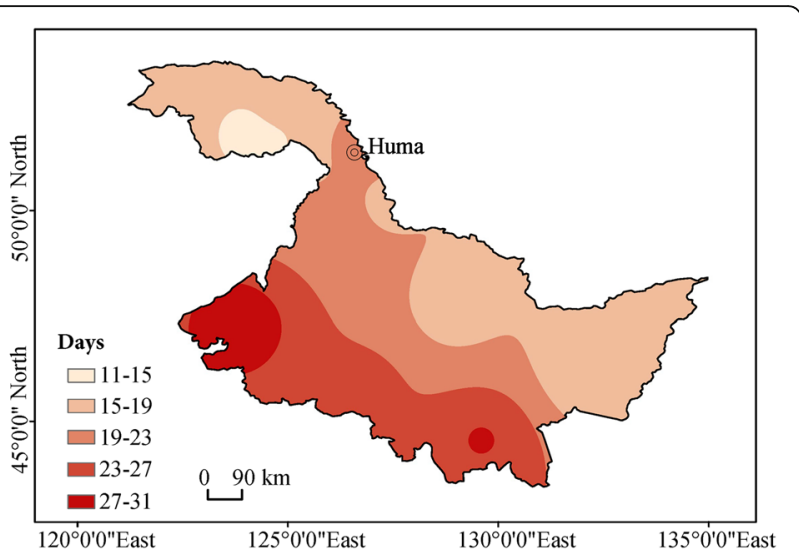

b) Distribution of high temperature duration

Fig. 7 Analysis scenario of once in a hundred years (Case 2). a Distribution of extreme high temperature. $\mathbf{b}$ Distribution of high temperature duration

$$
R_{A}^{\text {Case2 }}=\left(\begin{array}{lllll}
0.2064 & 0.2855 & 0 & 0.1013 & 0.4067
\end{array}\right)
$$

According to the maximum membership degree principle, the membership degree of pavement vulnerability in Case 1 is 0.5081 , which corresponds to comment set $V_{4}$, and vulnerability index $V_{\text {case } 1}$ is 0.7016 based on Eq. 3, indicating severe vulnerability. The membership degree of pavement vulnerability in Case 2 is 0.4067 , which corresponds to comment set $V_{5}$, and the calculated vulnerability index $V_{\text {case } 2}$ is 0.8813 , indicating extreme vulnerability. Therefore, the same asphalt pavement is more vulnerable under extreme high temperature once in a hundred years than under once in 20 years, which is consistent with the facts. Thus, the proposed vulnerability assessment methodology is reasonable and feasible.

\section{Summary and conclusion}

For the vulnerability assessment of asphalt pavements in cold regions, a highly targeted vulnerability analysis methodology and an assessment index system were established in this study. Furthermore, the concept and process of vulnerability assessment for asphalt pavements in cold regions were clarified, addressing the vulnerability assessment of asphalt pavements in cold regions to some extent. On the one hand, the system could provide a quantitative method of pavement performance assessment through the methodology and vulnerability assessment indices and realize the transformation from qualitative analysis to quantitative risk assessment. On the other hand, the proposed vulnerability assessment method could be used as a reference for risk prevention and maintenance decisions. Especially for severely cold regions, the vulnerability index calculated by this methodology could be used to judge the vulnerability of local road networks and infrastructure to formulate safe and reasonable maintenance strategies and resource allocation.

First, the concept of highway vulnerability, which refers to the nature of highway structures of being difficult to maintain serviceability state due to structural damage or disasters under harsh environments, is proposed.

Second, a three-stage vulnerability assessment model of asphalt pavements composed of exposure-fragilityresilience was established, and the assessment indices of exposure, vulnerability, and resilience were studied. The assessment index of pavement exposure is related to extreme climate. The extremely low temperature climate indices include extreme minimum temperature, low temperature duration, and daily temperature difference. The extremely high temperature climate indices include extreme maximum temperature, high temperature duration, annual average solar radiation and route design. The extremely rainfall climate indices include the average annual rainstorm days, the pavement drainage capacity, topography conditions, and geotechnical types. The indices of extreme freeze-thaw days include freezethaw days, the permafrost characteristics, and blizzard frequency. The assessment indices of pavement fragility include the pavement surface damage and the pavement's structural performance, and the specific index should be selected with the identification results of the pavement vulnerability characteristics. The assessment index of pavement resilience includes maintenance strength and maintenance effect.

Eventually, the calculation method of index weight and vulnerability index were proposed based on the AHP-fuzzy comprehensive evaluation method to realize the vulnerability assessment of asphalt pavements in cold regions. The extremely high temperature climate 
was selected as an example to analyze the vulnerability through the proposed vulnerability assessment methodology. The results indicate that the proposed vulnerability assessment methodology is reasonable and reliable.

In addition, other factors that may lead to pavement vulnerability could also be studied systematically according to the proposed methodology. To accurately obtain the vulnerability and service status of asphalt pavements in cold regions in a timely manner, a real-time online monitoring system could be established with fiber Bragg grating sensing technology. The applicability and accuracy of the proposed vulnerability assessment methodology could be modified by the measured structural response and the meteorological data from the monitoring system.

\begin{abstract}
Abbreviations
V: Pavement vulnerability index; E: Exposure; I: Fragility; $R$ : Resilience; $S_{V}$ : The membership matrix of vulnerability; $S_{E}$ : The membership matrix of exposure; $S_{F}$ : The membership matrix of fragility; $S_{R}$ : The membership matrix of resilience; $\omega_{E}$ : The weight of exposure; $\omega_{F}$ : The weight of fragility; $\omega_{R}$ : The weight of resilience; $a_{i}$ : The lower bound of interval corresponding to vulnerability grade; $s_{v}$ : The maximum membership degree of pavement vulnerability; $x_{p}$ : The prediction value under the probability of $p_{;} \bar{x}$ : The average of the historical data; $\Phi$ : The deviation coefficient; $C_{v}$ : The coefficient of variation; $x_{i}$ : The historical data, $i=1, \ldots, n ; n$ : The total data; $R_{C 1-U}^{\text {Case1: The }}$ membership matrix of pavement exposure in Case $1 ; R_{C 1-U}^{\text {Case2 }}$ : The membership matrix of pavement exposure in Case 2; $R_{\mathrm{Ci}-U}$ : The membership matrix of $\mathrm{Ci}$ $\mathrm{U}$ layer; $\omega_{C-\text { - }}$ : Indicator weight of $\mathrm{Ci}-\mathrm{U}$ layer; $\omega_{B i-C}$ Indicator weight of $\mathrm{Bi}-\mathrm{C}$ layer; $R_{B i-C}:$ The membership matrix of Bi-C layer; $R_{B i}$ : The membership matrix of Bi layer; $R_{A-B}^{\text {Case1: }}$ : The membership matrix of pavement vulnerability in Case 1; $R_{A-B}^{\text {Case2 }}$ : The membership matrix of pavement vulnerability in Case 2; $\omega_{A-B}$ : The weight of membership matrix of pavement vulnerability; $R_{A}^{\text {Case1 }}$ : The membership matrix of vulnerability in Case $1 ; R_{A}^{\text {Case2 }}$ : The membership matrix of vulnerability in Case 2
\end{abstract}

\section{Acknowledgements}

The author acknowledges the editorial assistance from Zhiyang Liu and Chen Yang of transportation science and engineering at Harbin Institute of Technology, and the format editing of references from Weiwen Quan of transportation science and engineering at Harbin Institute of Technology.

\section{Authors' contributions}

Tongxu Wang conducted the case analysis of the extreme high temperature climate and wrote the draft. Huanyu Li proposed the vulnerability assessment methodology. Xianyong Ma carried out field investigation and language editing. Zejiao Dong developed the research plan and language editing. The authors read and approved the final manuscript.

\section{Funding}

This work was supported by the National Key R \& D Program of China (No. 2018YFB1600100). Besides, this work was supported by the National Natural Science Foundation of China (No. U20A20315 and 51878228) and Outstanding youth fund of Heilongjiang Natural Science Foundation (JC2018013)

\section{Availability of data and materials}

All data used or generated by this study is available from the corresponding author by reasonable request.

\section{Declarations}

Ethics approval and consent to participate Not applicable.
Consent for publication

Not applicable.

\section{Competing interests}

The authors declare that they have no competing interests.

Received: 23 February 2021 Accepted: 6 April 2021

Published online: 16 April 2021

\section{References}

1. Marco AJ, Michael LS, Weimao K et al (2006) Scholarly networks on resilience, vulnerability and adaptation within the human dimensions of global environmental change. Glob Environ Change 16(3):240-252. https:// doi.org/10.1016/j.gloenvcha.2006.04.001

2. Timmerman P (1981) Vulnerability. Resilience and the collapse of socieiy: a review of models and possible climatic applications. I Environ Stud 1(4). https://doi.org/10.1002/joc.3370010412

3. Turner BLI, Kasperson RE, Matson PA et al (2003) A framework for vulnerability analysis in sustainability science. Proc Natl Acad Sci 100(14): 8074-8079. https://doi.org/10.1073/pnas.1231335100

4. Cutter SL (2003) The vulnerability of science and the science of vulnerability Ann Am Assoc Geogr 93(1):1-12. https://doi.org/10.1111/1467-8306.93101

5. Dow K (1992) Exploring differences in our common futures: the meaning of vulnerability to global environmental change. Geoforum 23(3):417-436. https://doi.org/10.1016/0016-7185(92)90052-6

6. Adger WN (1999) Social vulnerability to climate change and extremes in coastal Vietnam. World Dev 27(2):249-269. https://doi.org/10.1016/S0305750X(98)00136-3

7. Fatemi F, Ardalan A, Aguirre B, Mansouri N, Mohammadfam I $(2016,2016)$ Social vulnerability indicators in disasters: findings from a systematic review. Int J Disaster Risk Reduct:S2212420916302746. https://doi.org/10.1016/j.ijdrr.2 016.09 .006

8. Li H (2008) Concepts and assessment methods of vulnerability. Prog Geogr 27(2):18-25

9. $\quad$ Shang Y (2013) Overview of disaster vulnerability conceptual model. J Disaster Sci 28(1):112-116

10. Shi Y (2010) A study on urban vulnerability assessment under disaster scenarios. Dissertation. J East China Normal Univ (Nat Sci). https://doi.org/1 0.3969/j.issn.1000-811X.2013.01.024

11. Georgina C, Jesús MM, Carolina S et al (2016) At risk. Natural hazards, people's vulnerability and disasters. Econ Geogr 72(4):460-463

12. Saarinen TF, Hewitt K, Burton I (1973) The hazardousness of a place: a regional ecology of damaging events. Geogr Rev 63(1):134

13. Cutter SL, Boruff BJ, Shirley WL (2003) Social vulnerability to environmental hazards. Soc Sci Q 84(2):242-261. https://doi.org/10.1111/1540-6237.8402002

14. Dang ES, Wen-Jia HU, Chen GL, et al (2017) Assessment of ecological vulnerability in coastal zone of Dongshan Country based on VSD model. Mar Environ Sci 36(2):296-302

15. Moreno A, Becken S (2009) A climate change vulnerability assessment methodology for coastal tourism. J Sustain Tour 17(4):473-488. https://doi. org/10.1080/09669580802651681

16. Yin C (2013) Study on Hazard Assessment and Zoning of Highway Geological Hazards. Dissertation, Chang'an Univ, Xi'an, P.R. China

17. Li J, Yin C (2015) Highway natural disaster vulnerability assessment. J Beijing Univ Technol 41(7):1067-1072. https://doi.org/10.11936/bjutxb2014120077

18. Willway T, Baldachin $L$ (2008) The effects of climate change on highway pavements and how to minimise them: technical report. Transport Res Lab, UK

19. Qi H (2015) China Highway Geological Hazard Zoning Based on ArcGIS. J Chang'an Univ: Nat Sci (35):27. https://doi.org/10.19721/j.cnki.1671-8879.201 5.05 .004

20. Ma B (2011) Research on Identification Technology of Road Flood Disaster. Dissertation, Chang'an Univ, Xi'an, P.R. China

21. Xie B (2009) Study on Assessment Index and Method of Geological Hazard of Highway Subgrade. Dissertation, Chang'an Univ, Xi'an, P.R. China

22. Zhu J (2017) Research on Comprehensive Influence of Extreme Climate and Load on Asphalt Pavement. Dissertation, Chang'an Univ, Xi'an, P.R. China

23. Chen S, You Z, Sharifi NP, Yao H, Gong F (2019) Material selections in asphalt pavement for wet-freeze climate zones: a review. Constr Build Mater 201:510-525. https://doi.org/10.1016/j.conbuildmat.2018.11.276 
24. Berdica K (2002) An introduction to road vulnerability: what has been done, is done and should be done. Transp Policy 9(2):117-127. https://doi.org/10.1 016/S0967-070X(02)00011-2

25. Dong J, Jing W, Lu Q (2015) Road network vulnerability assessment considering congestion transmission effect. J Chongqing Univ Technol 029(008):55-60

26. Xiao Y (2013) Comprehensive Vulnerability Assessment Model of Urban Road Network Based on Complex Network Theory. Dissertation, Huazhong Univ Sci Technol, Wuhan, P.R. China

27. Husdal J (2004) Reliability and vulnerability versus costs and benefits. In: International Symposium on Transportion Network Reliability, New Zealand, 2004

28. Zhang R (2011) Research on Temperature Field Distribution Law of Road Structure in Seasonal Frozen Zone Considering Extreme Climate. Dissertation, Harbin I Technol, Harbin, P.R. China

29. Xu H, Tan Y, Zhang R et al (2014) Extreme low temperature weather and its influence on temperature and humidity distribution of road structure. China J Highw Transp 027(001):15-22

30. Hou W (2009) Detection and assessment methods of extreme events and spatio-temporal variations of extreme temperature and precipitation events in China in recent 40 years. Dissertation, Lanzhou Univ, Lanzhou, P.R. China

31. Ci DD (2016) Analysis and Prevention of Highway Subgrade Diseases in Qinghai-Tibet Permafrost Region. Dissertation, Chang'an Univ, Xi'an, P.R. China

32. Haas RCG, Phang WA (1970) Case studies of pavement shrinkage cracking as feedback for a design subsystem. Highway Res Rec 313:32-43

33. Gao C (2006) Research on Control Index and Prediction Model of Shrinkage and Crack at Low Temperature for Asphalt Pavement. Dissertation, Harbin I Technol, Harbin, P.R. China

34. He W (2016) Fatigue Damage Analysis of Semi-rigid Asphalt Pavement. Dissertation, Chongqing Jiaotong Univ, Chongqing, P.R. China

35. Liu Y, Li Y, Li Y et al (2017) Study on disaster vulnerability of hilly road in mountainous area based on AHP-fuzzy comprehensive assessment method - a case study of Xiuwu county, Henan province. J Disaster Sci 032(002):3238

\section{Publisher's Note}

Springer Nature remains neutral with regard to jurisdictional claims in published maps and institutional affiliations.

\section{Submit your manuscript to a SpringerOpen ${ }^{\circ}$ journal and benefit from:}

- Convenient online submission

- Rigorous peer review

- Open access: articles freely available online

- High visibility within the field

- Retaining the copyright to your article

Submit your next manuscript at $\boldsymbol{\nabla}$ springeropen.com 